\title{
A Decade of Research Advancements in the Legacy of Terrance J. Beveridge - An Integrated View of Prokaryotic Life
}

\author{
Guest Editors \\ Susan F. Koval \\ University of Western Ontario \\ Department of Microbiology and Immunology \\ London, Ontario, Canada \\ Cezar M. Khursigara \\ University of Guelph \\ Department of Molecular and Cellular Biology \\ Guelph, Ontario, Canada
}




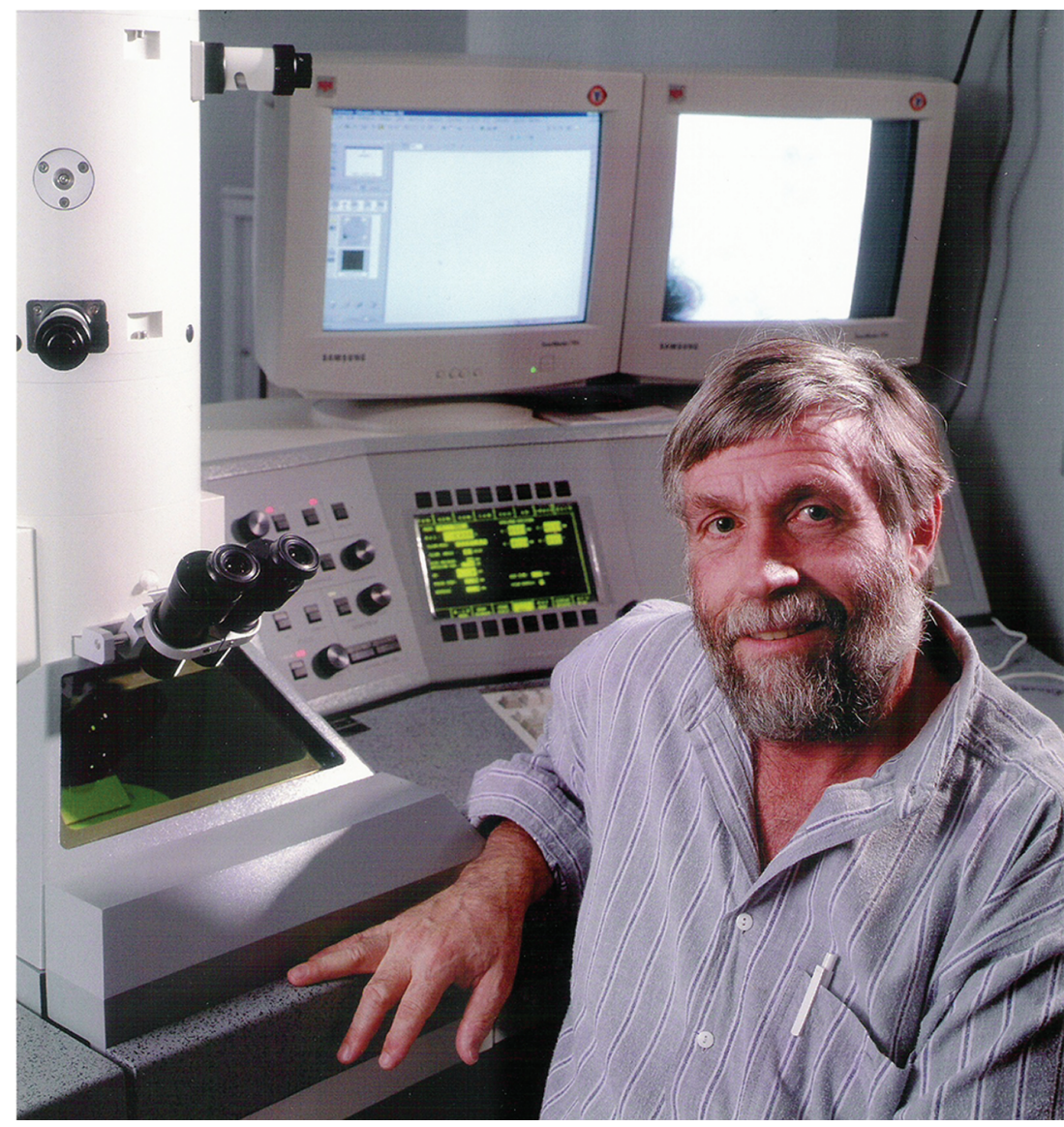

Terrance James Beveridge
1945-2007 